\title{
Regulation of Matrix Gla Protein by Parathyroid Hormone in MC3T3-E1 Osteoblast-Like Cells Involves Protein Kinase A and Extracellular Signal-Regulated Kinase Pathways
}

\author{
Supaporn Suttamanatwong, ${ }^{1}$ Renny T. Franceschi, ${ }^{2}$ Ann E. Carlson, ${ }^{1}$ and Rajaram Gopalakrishnan ${ }^{1}$ * \\ ${ }^{1}$ Department of Diagnostic and Biological Sciences, University of Minnesota School of Dentistry, \\ Minneapolis, Minnesota 55455 \\ ${ }^{2}$ Department of Periodontics and Oral Medicine, University of Michigan School of Dentistry, \\ Ann Arbor, Michigan 48109
}

\begin{abstract}
Inhibition of osteoblast-mediated mineralization is one of the major catabolic effects of parathyroid hormone (PTH) on bone. Previously, we showed that PTH induces matrix $\gamma$-carboxyglutamic acid (Gla) protein (MGP) expression and established that this induction is critical for PTH-mediated inhibition of osteoblast mineralization. In the present study, we focus on the mechanism through which PTH regulates MGP expression in osteoblastic MC3T3-E1 cells. Following transient transfection of these cells with a -748 bp murine MGP promoter-luciferase construct (pMGP-luc), PTH $\left(10^{-7} \mathrm{M}\right)$ induced promoter activity in a time-dependent manner with a maximal four- to six fold induction seen $6 \mathrm{~h}$ after PTH treatment. Both H-89 (PKA inhibitor) and U0126 (MEK inhibitor), suppressed PTH induction of MGP promoter activity as well as the MGP mRNA level. In addition, forskolin (PKA activator) stimulated MGP promoter activity and mRNA levels confirming that PKA is one of the signaling molecules required for regulation of MGP by PTH. Cotransfection of MC3T3-E1 cells with pMGP-luc and MEK(SP), a plasmid encoding the constitutively active form of MEK, led to a dose-dependent increase in MGP promoter activity. Both MGP promoter activity and MGP mRNA level were not affected by the protein kinase C (PKC) inhibitor, GF109203X. However, phorbol 12-myristate 13-acetate (PMA), a selective PKC activator induced MGP mRNA expression through activation of extracellular signal-regulated kinase (ERK). Taken together, these results indicate that PTH regulates MGP via both PKA- and ERK-dependent pathways. J. Cell. Biochem. 102: 496-505, 2007. (c) 2007 Wiley-Liss, Inc.
\end{abstract}

Key words: parathyroid hormone; matrix gla protein; protein kinase A; protein kinase C; extracellular signal-related kinase; osteoblast

Parathyroid hormone (PTH) functions as a key regulator of calcium homeostasis by acting through its target organs, that is, bone, kidney, and intestine, to increase serum calcium levels. In bone, PTH serves as a major mediator of bone remodeling. The in vivo effects of PTH on bone

Grant sponsor: NIH; Grant number: DE016093; Grant sponsor: University of Minnesota.

*Correspondence to: Rajaram Gopalakrishnan, BDS, PhD, Department of Diagnostic and Biological Sciences, University of Minnesota School of Dentistry, 16-108B Moos Tower, 515 Delaware St. SE, Minneapolis, MN 55455, USA E-mail: gopal007@umn.edu

Received 2 October 2006; Accepted 30 January 2007

DOI 10.1002/jcb.21314

(c) 2007 Wiley-Liss, Inc. can be either anabolic or catabolic, depending on dosage, method of delivery, and frequency of treatment [Tam et al., 1982]. Intermittent low dose administration of PTH in vivo promotes bone formation while continuous treatment results in bone loss [Ishizuya et al., 1997; Jilka et al., 1999]. Continuous exposure to PTH in vitro has been shown to inhibit osteoblast differentiation and mineralization in primary calvarial osteoblasts, calvarial explants, and osteoblast-like cell lines [Bellows et al., 1990; Pfeilschifter et al., 1990; Ishizuya et al., 1997; Koh et al., 1999; Wang et al., 2000].

In osteoblasts, actions of PTH are mediated by the PTH1 receptor (PTH1R), a seven transmembrane domain G-protein coupled receptor expressed on the cell surface. PTH treatment is known to stimulate three major signaling 
cascades leading to activation of protein kinase A (PKA), protein kinase C (PKC), and extracellular signal-regulated kinase (ERK) pathways [Partridge et al., 1994; Swarthout et al., 2002]. Following activation of these signaling pathways, PTH regulates its target genes by activation of several transcription factors [Partridge et al., 1994]. The cAMP response element binding protein (CREB), activator protein-1 (AP-1) transcription factors, and RUNX2 are among the most widely studied PTH-responsive transcription factors in osteoblasts. Post-translational modifications such as phosphorylation are required for activation of these transcription factors, which in turn regulate changes in gene expression.

Matrix $\gamma$-carboxyglutamic acid (Gla) protein (MGP) is a vitamin $\mathrm{K}$-dependent protein found in hypertrophic chondrocytes, cementum, vascular smooth muscle cells, and bone [Price, 1989; Sato et al., 1998]. MGP is produced by a variety of cell types in culture, including osteoblasts, chondrocytes, vascular smooth muscle cells, and endothelial cells [Fraser et al., 1988; Barone et al., 1991; Engelse et al., 2001; Gopalakrishnan et al., 2001]. MGP functions as an inhibitor of mineralization both in vitro and in vivo [Luo et al., 1997]. Retrovirusmediated overexpression of MGP greatly decreased mineralization in cultured chondrocytes and inhibited cartilage mineralization as well as endochondral ossification in developing chick limb bud [Yagami et al., 1999]. Major in vivo evidence that further substantiates the role of MGP as a potent mineralization inhibitor comes from studies in MGP-deficient mice. These mice exhibit abnormal calcification of cartilage and extensive mineralization of arteries [Luo et al., 1997]. Mutation of the MGP gene in humans results in Keutel syndrome, an autosomal recessive disorder characterized by abnormal cartilage calcification, peripheral pulmonary stenosis, and midfacial hypoplasia [Munroe et al., 1999].

Although several studies have been published, investigating the regulation of MGP expression in chondrocytes, vascular smooth muscle cells, and endothelial cells by several growth factors and hormones such as retinoic acid, TGF $\beta$, FGF2, and thyroid hormone [Cancela and Price, 1992; Kirfel et al., 1997; Stheneur et al., 2003; Sato et al., 2005], not much is known about regulation of MGP in osteoblasts. Previously, we showed that MC3T3-E1 osteoblast-like cells express MGP, and PTH treatment induces MGP mRNA level in a timeand dose-dependent manner [Gopalakrishnan et al., 2001]. We also showed that MGP is a key regulator in PTH-mediated inhibition of mineralization in these cells. To further understand the mechanism by which PTH regulates MGP expression in osteoblasts, we investigated the signaling pathways involved in PTH regulation of MGP mRNA level and promoter activity in MC3T3-E1 cells. Our studies show that actions of PTH on MGP can be explained, at least in part, by stimulation of MGP promoter activity. Furthermore, this activation is mediated by both PKA- and ERK/MAPK pathways.

\section{EXPERIMENTAL PROCEDURES}

\section{DNA Constructs}

The murine Mgp promoter construct, pMGPluc, containing bases -748 to +1 of the murine $M g p$ gene was derived from pMGP2 and subcloned into the HindIII site of pGL3Basic (Promega, Madison, WI) upstream of the firefly luciferase reporter gene. The plasmid pMGP2 was a gift from Dr.Gerard Karsenty (Baylor University, Houston, TX) [Luo et al., 1995]. pCMV5-MEK(SP), a plasmid encoding constitutively active mutant of MEK, was kindly provided by Dr. Kun-Liang Guan (University of Michigan, Ann Arbor, MI) and was used as described previously [Xiao et al., 2000].

\section{Cell Culture}

A highly differentiating subclone of MC3T3E1 cells (MC-14) was used for the studies [Wang et al., 1999; Petryk et al., 2005]. MC3T3-E1 cells express most of the known osteoblast markers and form a mineralized ECM following differentiation in AA-containing medium. MC3T3-E1 cells were maintained in MEM media containing $10 \% \mathrm{FBS}, 1 \%$ penicillin/streptomycin, $1 \%$ non-essential amino acids, and were not used beyond passage 20. For all experiments except those involving transfection, cells were plated at 50,000 cells $/ \mathrm{cm}^{2}$ and treatments performed in $0.1 \%$ FBS containing MEM. Experiments involving signaling inhibitors were pretreated for 30 min with signaling inhibitors. The following specific activators and inhibitors for each signaling pathway were used; PKA inhibitor (H-89); PKC inhibitors (GF109203X); MEK/ ERK inhibitors (U0126); PKA activators (forskolin and 8-Br cAMP); and PKC activator 
[phorbol 12-myristate 13-acetate (PMA)]. For experiments involving transfection, MC3T3-E1 cells were plated at a density of 25,000 cells $/ \mathrm{cm}^{2}$ in 35-mm dishes.

\section{Western Blot Analysis}

MC3T3-E1 cells were serum starved for $24 \mathrm{~h}$, following which cells were pretreated with the indicated concentration of GF109203X or U0126 for 30 min in AA-free MEM containing $0.1 \%$ FBS. After 30 min, PMA or DMSO as control, were added in the media for $10 \mathrm{~min}$. Whole cell extracts were harvested in 1X lysis buffer $[100 \mathrm{mM}$ tris(hydroxymethyl)aminomethane (Tris, $\mathrm{pH} 7.4$ ), $100 \mathrm{mM} \mathrm{NaCl}, 1 \mathrm{mM}$ ethylenediamine-tetra acetic acid (EDTA), $1 \mathrm{mM}$ ethyleneglycol-tetra acetic acid (EGTA), $1 \mathrm{mM} \mathrm{NaF}, 20 \mathrm{mM} \mathrm{NaP} \mathrm{O}_{4}, 2 \mathrm{mM} \mathrm{Na}_{3} \mathrm{VO}_{4}, 1 \%$ Triton X-100, $10 \%$ glycerol, $0.1 \%$ sodium dodecyl sulfate (SDS), $0.5 \%$ deoxycholate, $1 \mathrm{mM}$ PMSF, and protease inhibitors (protease inhibitor cocktail tablets, Boehringer Mannheim, 1 tablet $/ 10 \mathrm{ml}$. Proteins were separated by $12 \%$ SDS-PAGE and transferred to a PVDF membrane (Millipore, Billerica, MA). Immunoblotting was performed as previously described [Petryk et al., 2005], with anti-total ERK 1/2 and phosphorylated ERK1/2 antibodies and horseradish peroxidase-conjugated secondary antibodies. Immunoreactive bands were then visualized by chemiluminescence using ECL kit (Amersham Pharmacia Biotech).

\section{RNA Isolation and Northern Blot Analysis}

Total RNA was extracted using TRIzol reagent (Invitrogen Life Technologies, Carlsbad, CA) according to manufacturer's directions and quantified by UV spectrophotometry. Northern blot analysis was performed as previously described [Gopalakrishnan et al., 2001; Petryk et al., 2005]. Fifteen microgram aliquots of total RNA were fractionated on $0.8 \%$ agaroseformaldehyde gels, transferred to nitrocellulose membranes and UV cross-linked. MGP cDNA was obtained from Dr. Gerard Karsenty (Baylor College of Medicine, Houston, TX) [Luo et al., 1995]. The membrane was hybridized with a ${ }^{32} \mathrm{P}$-labeled mouse MGP cDNA probe labeled with $\left[\alpha-{ }^{32} \mathrm{P}\right]$ deoxy-CTP (Amersham Biosciences/GE Healthcare, Piscataway, NJ) using a random primer labeling kit (Invitrogen Life Technologies). All blots were normalized for RNA loading by stripping and reprobing with cDNA to 18S rRNA [Renkawitz et al., 1979].

\section{Real-Time RT-PCR}

Reverse transcription of extracted mRNA was performed using $1 \mu \mathrm{g}$ of denatured RNA and $100 \mathrm{pmol}$ of random hexamers (Invitrogen Life Technologies) in a $20 \mu \mathrm{l}$ total volume containing 50 U Super Script reverse transcriptase (Invitrogen Life Technologies). Quantitative RT-PCR was performed as previously described using MX MX 3000 ${ }^{\mathrm{TM}}$ real-time PCR System (Stratagene Corporation, La Jolla, CA) using $1 \mu \mathrm{l}$ of the cDNA equivalent to $50 \mathrm{ng}$ mRNA with 1x Brilliant SYBR Green master mix and ROX reference dye (1:500) (Stratagene, La Jolla, CA) [Gopalakrishnan et al., 2005]. The final reaction volume was $25 \mu \mathrm{l}$, and each sample was run in duplicates for both MGP and GAPDH, which was used as a house keeping gene. MGP primer sequences were used as previously published [Newman et al., 2001]. The mRNA levels were normalized by using mouse GAPDH as housekeeping gene and compared with levels of mouse total RNA (Stratagene). The fold change was calculated using the control sample Ct values at each specified time point as a calibrator by means of $2^{-\Delta \Delta \mathrm{CT}}$ method.

\section{Transfection and Luciferase Activity Assay}

Twenty-four hours after plating, MC3T3-E1 cells were co-transfected, using Lipofectamine (Invitrogen, Carlsbad, CA), with $1 \mu \mathrm{g} /$ dish of pMGP-luc promoter construct and $0.05 \mu \mathrm{g} / \mathrm{dish}$ of pRL-SV40 Renilla luciferase vector (Promega) for normalization of transfection. Four hours later, transfection media was replaced by MEM containing $10 \%$ FBS overnight. The following day, cells were treated with vehicle, PTH $\left(10^{-7} \mathrm{M}\right)$ or signaling activators in MEM containing $0.1 \%$ FBS. In experiments using signaling inhibitors, cells were pretreated with signaling inhibitors or DMSO for $30 \mathrm{~min}$ followed by vehicle or PTH $\left(10^{-7} \mathrm{M}\right)$ treatment. For overexpression of MEK(SP), cells were cotransfected with $1 \mu \mathrm{g} /$ dish of pMGP-Luc promoter construct and $0.1-0.5 \mu \mathrm{g} / \mathrm{dish}$ of pCMVMEK(SP) plus $0.05 \mu \mathrm{g} /$ dish of pRL-SV40 Renilla luciferase vector (Promega) for normalization of transfection. Four hours later, transfection media was replaced by MEM containing $10 \%$ FBS. Cell lysates were harvested $48 \mathrm{~h}$ after transfection. Luciferase activity in cell lysates were assayed using the Dual Luciferase Reporter kit (Promega) and EG\&G Berthold Lumat 
LB9507 luminometer according to the manufacturer's instruction.

\section{Statistical Analysis}

All transfection experiments were performed in triplicate and repeated at least three times. Data represented as mean $\pm \mathrm{SD}$ will be analyzed using Student $t$-test or one-way ANOVA followed by Tukey-Kramer multiple comparison test to determine significance between groups.

\section{RESULTS}

\section{PTH Induction of Mgp Promoter Activity}

Prior to a more detailed analysis of the PTHresponsive elements in the $M g p$ promoter, we investigated whether PTH can affect $M g p$ promoter activity. A $-748 \mathrm{bp}$ portion of the Mgp promoter was previously shown to be transcriptionally active when transiently transfected into MGP-expressing UMR106-01 cells, but was not active in a lymphocyte cell line that does not express MGP [Luo et al., 1995]. In addition, this promoter fragment contains sufficient information for transcriptional activation by FGF2 in proliferative chondrocytes [Stheneur et al., 2003]. To evaluate actions of PTH on this promoter, pMGP-Luc plasmid was transiently transfected into MC3T3-E1 cells followed by treatment with vehicle or PTH $\left(10^{-7} \mathrm{M}\right)$. As expected, PTH treatment induced the $-748 \mathrm{bp}$ $M g p$ promoter activity in MC3T3-E1 cells in a time-dependent manner with approximately threefold induction seen after $3 \mathrm{~h}$ (Fig. 1). The

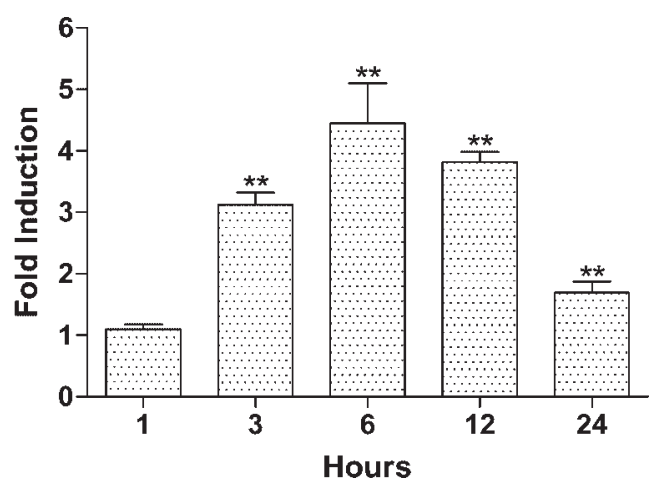

Fig. 1. Effect of PTH (1-34) on -748 bp Mgp promoter activity. MC3T3-E1 cells were co-transfected with $0.05 \mu \mathrm{g}$ pRL-SV40 and $1 \mu \mathrm{g}$ pMGP-luc using lipofectamine and treated with PTH $\left(10^{-7} \mathrm{M}\right)$ or vehicle in MEM containing $0.1 \%$ FBS for the indicated time. Data represent relative fold induction compared with vehicletreated group. Error bars represent standard deviation. ${ }^{* *}, P<$ 0.01 (significantly different from vehicle treated group). maximal induction was approximately four- to sixfold at $6 \mathrm{~h}$ after treatment and the activity gradually declining to baseline levels by $24 \mathrm{~h}$. We also found that PTH does not have any effect on the activity of pGL3Basic empty vector (data not shown).

\section{PTH Induction of MGP Promoter Activity and MGP mRNA Requires PKA and ERK/MAPK Pathways}

To identify the signaling pathways involved in PTH regulation of MGP, we used specific inhibitors for the three signaling pathways known to be activated by PTH, that is, PKA, PKC, and ERK pathways. Appropriate dosages of each inhibitor were established using Western blot analysis of the phosphorylation of known target proteins. For these studies, we measured H-89 inhibition of PKA-dependent phosphorylation of CREB with or without PTH stimulation, GF109203X inhibition of PKCdependent ERK1/2 phosphorylation (using PMA as inducer) and U0126 inhibition of FBS induction of MEK-dependent ERK1/2 phosphorylation (data not shown). For each inhibitor, the minimal effective dose to inhibit target protein phosphorylation was chosen for the experiments to investigate the signaling pathways involved in MGP induction by PTH.

As shown in Figure 2A, H-89, a PKA-specific inhibitor, dramatically inhibited PTH-induced MGP promoter activity in a dose-dependent manner $(1-10 \mu \mathrm{M})$. Similar results were obtained with U0126, an ERK inhibitor, although inhibition was less-complete than that for H-89. In contrast, the PKC inhibitor, GF109203X (0.1-1 $\mu \mathrm{M})$ did not have a significant effect on the PTH-induced MGP promoter activity. Similar results were obtained when MGP mRNA were measured by Northern blot (Fig. 2B) and real-time RT-PCR analysis (Fig. 2C). H-89 $(10 \mu \mathrm{M})$ and U0126 $(10 \mu \mathrm{M})$ inhibited MGP induction of mRNA expression following PTH treatment. However, GF109203X $(1 \mu \mathrm{M})$, a PKC inhibitor failed to inhibit PTH induction of MGP mRNA expression. These results suggest that PKA and ERK-pathways are more likely involved in PTH regulation of MGP expression.

\section{Activation of PKA and ERK Pathways Induced MGP mRNA and MGP Promoter Activity}

To confirm the inhibitor studies, we used activators of signaling pathways to induce MGP 
A
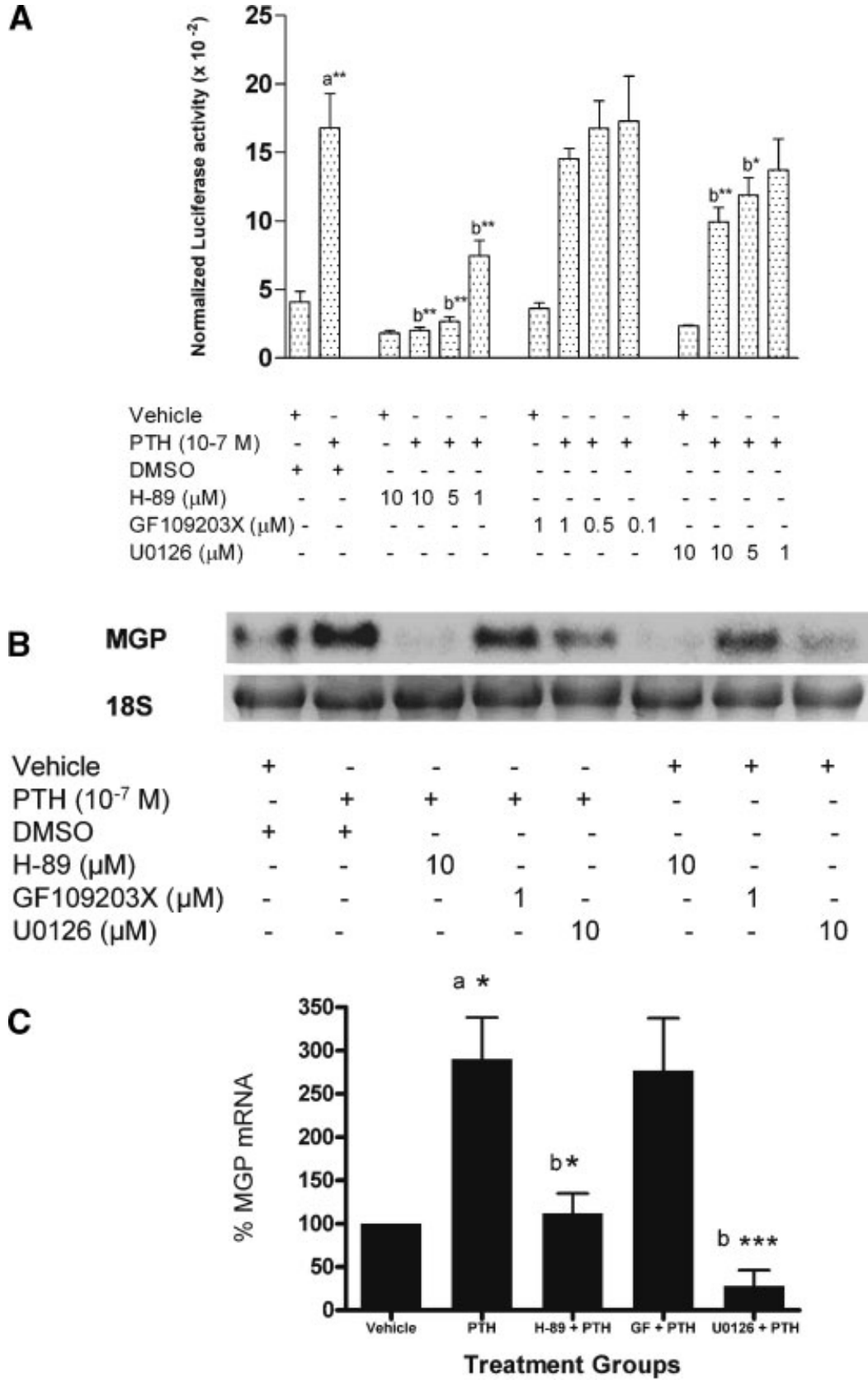

Fig. 2. $P K A$ and ERK but not PKC inhibitors blocked PTH induction of MGP. A: MC3T3-E1 cells were transfected with $1 \mu \mathrm{g}$ pMGP-luc using lipofectamine and treated with PTH $\left(10^{-7} \mathrm{M}\right)$ or vehicle in MEM containing $0.1 \% \mathrm{FBS}$ in the presence of varying concentrations of H-89, GF109203X, or U0126 for 6 h. All values are represented as mean $\pm \mathrm{SD}$ from triplicate samples. B: Northern blot analysis and $(\mathbf{C})$ real-time RT-PCR analysis of

expression and promoter activity. We found that PKA activators, forskolin $(1 \mu \mathrm{M})$ and $8-\mathrm{Br}$ cAMP (3 mM), induced MGP promoter activity up to sixfold (Fig. 3A). Forskolin also induced MGP mRNA expression as shown by both Northern blot and real-time RT-PCR analysis
MGP mRNA expression following treatment with PTH in the presence or absence of inhibitors of PKA (H-89), PKC (GF109203X), and MAPK (U0126) pathways in MC3T3-E1 cells. Real-time RT-PCR values are mean \pm SD from three independent experiments. ${ }^{*}, P<0.05$; ${ }^{* * *} P<0.001$ (a, significantly different than vehicle treated group; $b$, significantly different from PTH group).

(Fig. 3B,C). Activation of the ERK pathway was achieved by overexpressing pCMV-MEK(SP), a plasmid encoding a constitutively active form of MEK, in MC3T3-E1 cells co-transfected with pMGP-luc. In these cells, MGP promoter activity was induced in a dose-dependent manner 


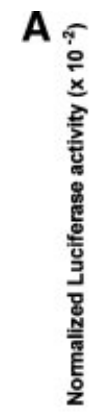

B

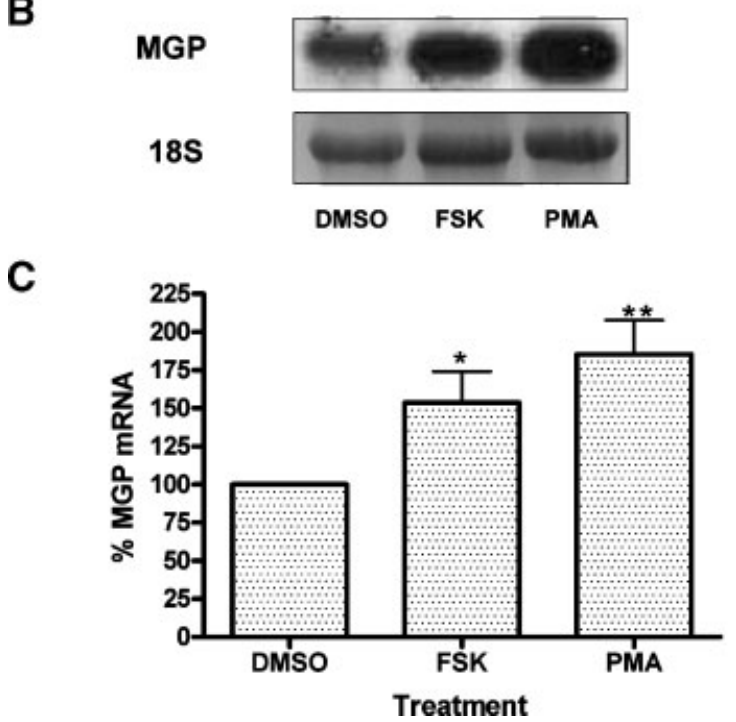

Fig. 3. A: PKA but not PKC activators induced MGP promoter activity. MC3T3-E1 cells were treated with vehicle, $1 \mu \mathrm{M}$ forskolin, $3 \mathrm{mM}$ 8-Br cAMP,or $10 \mu \mathrm{M}$ PMA in MEM containing $0.1 \%$ FBS for $6 \mathrm{~h}$. All values are the mean \pm SD of triplicate samples. Northern blot analysis (B) and real-time RT-PCR analysis (C) of MGP mRNA expression in MC3T3-E1 cells following treatment with DMSO, $1 \mu \mathrm{M}$ forskolin or $10 \mu \mathrm{M}$ PMA. Real-time RT-PCR values are mean \pm SD from three independent experiments. ${ }^{*}, P<0.05$; ${ }^{* *}, P<0.01$ (significantly different from vehicle-treated group).

(Fig. 4) indicating that the ERK pathway is involved in regulation of MGP transcription.

\section{Activation of PKC Pathway Induced MGP mRNA but not MGP Promoter Activity}

The inhibitor studies in Figure 2A,B showed that GF109203X did not affect PTH-induced MGP mRNA or promoter activity. Consistent with the inhibitor studies, activation of PKC pathway by PMA $(10 \mu \mathrm{M})$ does not have a significant effect on the MGP promoter activity (Fig. 3A). However, PMA (10 $\mu \mathrm{M})$ surprisingly increased MGP mRNA expression comparable to that induced by forskolin (Fig. 3B).

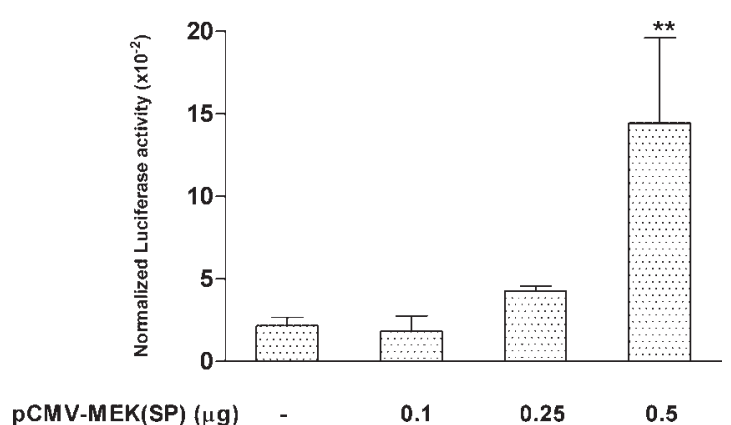

Fig. 4. ERK pathway activation dose-dependently induced MGP promoter activity. MC3T3-E1 cells were co-transfected with $1 \mu \mathrm{g}$ pMGP-luc and 0.1-0.5 $\mu \mathrm{g}$ pCMV-MEK(SP). Cell lysates were harvested $48 \mathrm{~h}$ after transfection. Data represent relative fold induction compared with $\mathrm{pCMV}$ - $\beta$ gal group. Error bars represent standard deviation. ${ }^{* *}, P<0.01$ (significantly different from control group).

\section{PKC Activation Stimulates ERK1/2 Phosphorylation in MC3T3-E1 Cells}

Evaluation of ERK1/2 activation by PMA was performed to explain a possible mechanism for induction of MGP mRNA expression by PMA. Recent reports have suggested that PTH signaling in osteoblasts involved cross-talk between multiple pathways [Swarthout et al., 2002]. Further, it has been reported that PTH treatment stimulated ERK activity in UMR-106 osteoblastic cells and this activation is PKCdependent [Swarthout et al., 2001]. Here we show that PMA-mediated activation of PKC pathway in MC3T3-E1 cells stimulated ERK1/2 phosphorylation (Fig. 5B). GF109203X dosedependently inhibited PMA-induced ERK1/2 phosphorylation suggesting that PMA-mediated ERK phosphorylation is dependent on one or more conventional PKC isozymes, that is, PKC alpha, betaI, betaII, and gamma (Fig.5B). U0126, a specific MEK inhibitor, also reduced PMA-induced ERK1/2 phosphorylation suggesting that MEK is also involved in PMAinduced ERK1/2 phosphorylation (Fig. 5C). To confirm whether MGP mRNA induction by PMA is mediated by ERK1/2 phosphorylation, we quantitated MGP mRNA expression by realtime RT-PCR analysis following co-treatment with PMA $(10 \mu \mathrm{M})$ and U0126 $(1-10 \mu \mathrm{M})$. As shown in Fig. 5A, U0126 significantly inhibited PMA-mediated induction of MGP mRNA expression in MC3T3-E1 cells. Therefore, we conclude that PMA activation of MGP mRNA expression is most likely mediated through ERK1/2 phosphorylation. 
A

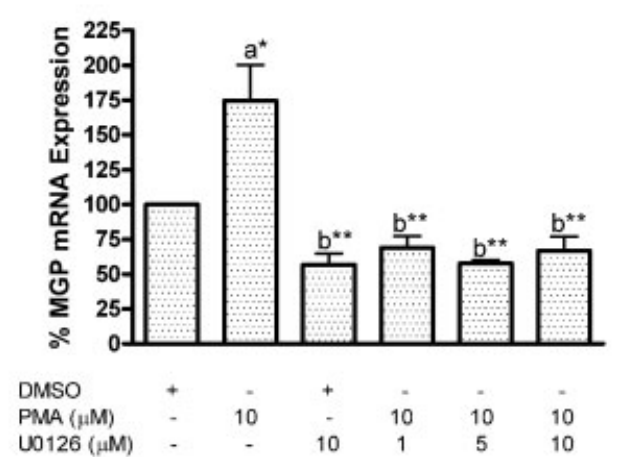

B

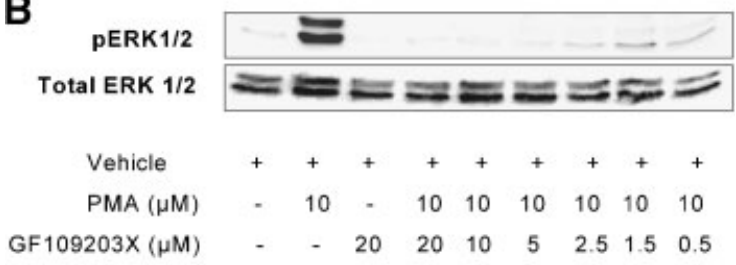

C

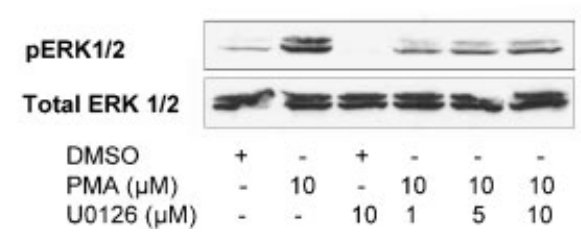

Fig. 5. PKC activation stimulates ERK1/2 phosphorylation in MC3T3-E1 cells through MEK. A: Real-time RT-PCR analysis showing MGP mRNA levels following treatment with PMA (10 $\mu \mathrm{M})$ and various doses of U0126 in MC3T3-E1 cells. All values are mean \pm SD from three independent experiments. B: Western blot analysis of pERK1/2 following treatment with PMA $(10 \mu \mathrm{M})$ alone or in the presence of various doses GF109203X in MC3T3E1 cells. C: Western blot analysis of pERK1/2 following treatment with PMA $(10 \mu \mathrm{M})$ alone or in the presence of various concentrations of U0126. *, $P<0.05$; **, $P<0.01$. (a, Significantly different than vehicle-treated group; $b$, significantly different from PMA-treated group).

\section{DISCUSSION}

In this study, we identify PKA and ERK as two signaling pathways involved in PTH regulation of MGP. Inhibition of PKA or ERK pathways drastically decreased PTH-induced MGP promoter activity as well as MGP mRNA expression. However, PKA appeared to be the primary pathway in this regulation, because MGP induction by PTH is more sensitive to H-89 than to the MEK inhibitor U0126, when used at their optimal doses. We also confirmed the results of these inhibitor studies by using selective signaling pathway activators. Stimulation of either PKA or ERK pathways dramatically increased MGP promoter activity. These results suggest the involvement of these two pathways in transcriptional regulation of MGP by PTH.

PKA has long been known as the major signaling pathway mediating most of biological effects of PTH [Swarthout et al., 2002]. Two activators of the PKA pathway, forskolin and 8-Br cAMP, were used in the current study. While forskolin directly activates adenylyl cyclase and thus raises cAMP level, 8-Br cAMP activates PKA by acting as a cAMP agonist [Insel and Ostrom, 2003]. We have shown that both forskolin and 8-Br-cAMP activate the pMGP-luc promoter. Our study also shows that forskolin increases MGP mRNA by approximately twofold. This result suggests that the inductive effect of PTH on MGP is, at least partially, PKA-dependent.

One of the consequences of PTH receptor activation is the production of diacylglycerol (DAG) which leads to activation of PKC [Civitelli et al., 1988; Civitelli et al., 1989; Dunlay and Hruska, 1990]. PMA can directly activate PKC by acting as a DAG analog. Here we show that PKC inhibition or activation does not have any effect on PTH-induced MGP promoter activity. However, we found that PMA treatment induces MGP mRNA levels comparable to forskolin treatment suggesting that PKC may be involved in MGP expression. Atleast two reasons can be proposed to explain why the PKC inhibitor, GF109203X, did not block PTH induction of MGP mRNA and promoter activity, while PMA activated only MGP mRNA expression, but not the MGP promoter activity. First, eleven different isozymes of PKC, alpha, betaI, betaII, gamma, delta, epsilon, nu, lambda(iota), $\mathrm{mu}$, theta, and zeta, have been identified [Liu and Heckman, 1998]. GF109203X inhibits only conventional PKC isozymes, that is, alpha, betaI, betaII, and gamma. However, PMA stimulates most of the isozymes except PKC zeta and PKC lambda [Liu and Heckman, 1998]. PTH on the other hand activates alpha, beta I, and delta [Dossing et al., 2001; Radeff et al., 2001; Erclik and Mitchell, 2002]. Therefore, it is possible that the inductive effect of PMA and PTH on MGP mRNA level is mediated through PKC isozyme(s) other than those inhibited by GF109203X. Second, induction of MGP expression by PMA maybe regulated at the posttranscriptional level, possibly by the stabilization of MGP mRNA, or by slowing down MGP mRNA degradation. Further, the inability of 
PMA to activate the -748 bp MGP promoter, in spite of inducing MGP mRNA expression, could possibly be due to the absence of necessary promoter elements in the analyzed pMGP-luc. A larger $5 \mathrm{~kb}$ promoter fragment can be utilized to further evaluate the regulatory elements involved in PKC activation of MGP.

In addition to PKA and PKC, the ERK pathway has recently been shown to be stimulated by PTH. Swarthout et al. [2001] reported that ERK activity is induced only by low $\left(10^{-12}\right.$ to $\left.10^{-11} \mathrm{M}\right)$ but not high $\left(10^{-8} \mathrm{M}\right)$ doses of PTH in UMR106 rat osteoblastic cells. In these cells, activation of ERK by PTH is MEK- and PKCdependent. Here, we found that U0126 inhibits PTH-induced MGP mRNA expression and promoter activity in MC3T3-E1 cells. Furthermore, we also show that ERK activation by pCMVMEK(SP) significantly induces MGP promoter activity, thereby suggesting a direct role for the ERK pathway in MGP regulation.

To further understand the mechanisms by which PTH or PMA induces MGP expression, we chose to investigate the connection between the PKC and ERK pathways. Based on our results, we speculate that ERK1/2 phosphorylation might be involved in MGP induction following PKC activation in MC3T3-E1 cells. As shown in Figure 5, PMA-mediated PKC activation induces MGP mRNA expression and U0126 inhibits this induction, suggesting that ERK phosphorylation is required for PKCmediated MGP induction. Western blot analysis confirms that ERK1/2 phosphorylation is induced by PMA treatment and this induction is mediated through PKC and MEK because both GF109203X and U0126 treatments inhibit PMA-induced ERK1/2 phosphorylation. Taken together, these results suggest that both PKC and MEK are required for PMA-induced ERK1/ 2 phosphorylation and MGP mRNA expression.

However, the regulation of MGP by PMA and ERK phosphorylation appears to be complicated and questions exist in answering some key aspects of this regulation. For instance, PMA can regulate MGP mRNA levels through phosphorylation of ERK, however, PMA does not regulate $M g p$ promoter while a constitutively active MEK does. Therefore, if PMA does phosphorylate ERK, and ERK activation is sufficient to activate Mgp promoter, why is PMA unable to activate the MGP promoter? As discussed earlier, an explanation for this finding could be that PMA most likely regulates
MGP expression through activation of ERK through DNA elements that are not present in the $-748 \mathrm{bp} M g p$ promoter. Another explanation would be that different ERK isoforms and/ or ERK substrates were activated by PMA versus constitutively active MEK. Even though the main cascade of ERK activation includes Raf, MEK 1/2, and ERK, several alternative spliced forms exist in different tiers. To date, eight members of the ERK family have been identified, ERK 1,2,3,4,5,6,7, and 8 [Bogoyevitch and Court, 2004] At least 160 substrates have been discovered for ERK [Yoon and Seger, 2006]. These components enhance the complexity of the ERK cascade and thereby the wide variety of functions of ERK family proteins.

PTH signaling in osteoblasts is quite complex and involves crosstalk between multiple pathways, that is, PKA, PKC, and ERK [Swarthout et al., 2002]. For example, prolonged activation of PKC by PMA significantly decreased PTHinduced production of cAMP, an upstream activator of PKA, in UMR106 osteoblastic cells [Sugimoto et al., 1994]. However, brief exposure to PMA augmented PTH-induced cAMP production in these cells. In addition, PKA activation can inhibit ERK activity in both MC3T3-E1 and UMR106 cells [Siddhanti et al., 1995; Verheijen and Defize, 1995]. In addition to cross-regulation, cooperation of these signaling pathways to regulate PTH-responsive gene expression has also been reported [Swarthout et al., 2002]. For example, PTH induction of collagenase-3 in differentiating osteoblasts involves both PKA and PKC pathways [Winchester et al., 1999]. PTH-mediated Smad-3 induction in MC3T3-E1 and UMR-106 osteoblastic cells requires PKA as well as $\mathrm{PKC}$ signaling [Sowa et al., 2003]. Consistent with our results, Jiang et al. [2004] has recently shown that PKA, PKC, and ERK are all important for PTH induction of osteocalcin in MC3T3-E1 cells. To date, PKA is considered the key pathway leading to PTH-mediated activation of CREB, AP-1, and RUNX2 transcription factors, and thus to changes in gene expression in osteoblasts. Unlike PKA, the consequence of PKC and ERK activation by PTH is just starting to be understood. More studies are needed to investigate the molecular events following activation of these pathways by PTH.

Here, we report that both PKA and ERK pathways play significant roles in PTH regulation of MGP. These results provide improved 
insight into the signaling mechanisms used by PTH in osteoblasts as well as important clues about regulation of MGP, to help determine the transcription factor(s) and DNA binding elements critical for PTH induction of MGP in osteoblasts.

\section{ACKNOWLEDGMENTS}

This work was supported by NIH grant no DE016093 and University of Minnesota Grantin-Aid to R.G.

\section{REFERENCES}

Barone LM, Owen TA, Tassinari MS, Bortell R, Stein GS, Lian JB. 1991. Developmental expression and hormonal regulation of the rat matrix Gla protein (MGP) gene in chondrogenesis and osteogenesis. J Cell Biochem 46: 351-365.

Bellows CG, Ishida H, Aubin JE, Heersche JN. 1990. Parathyroid hormone reversibly suppresses the differentiation of osteoprogenitor cells into functional osteoblasts. Endocrinology 127:3111-3116.

Bogoyevitch MA, Court NW. 2004. Counting on mitogenactivated protein kinases-ERKs 3, 4, 5, 6,7, and 8. Cell Signal 16:1345-1354.

Cancela ML, Price PA. 1992. Retinoic acid induces matrix Gla protein gene expression in human cells. Endocrinology 130:102-108.

Civitelli R, Hruska KA, Jeffrey JJ, Kahn AJ, Avioli LV, Partridge NC. 1989. Second messenger signaling in the regulation of collagenase production by osteogenic sarcoma cells. Endocrinology 124:2928-2934.

Civitelli R, Reid IR, Westbrook S, Avioli LV, Hruska KA. 1988. PTH elevates inositol polyphosphates and diacylglycerol in a rat osteoblast-like cell line. Am J Physiol 255:E660-E667.

Dossing DA, Radeff JM, Sanders J, Lee SK, Hsieh MR, Stern PH. 2001. Parathyroid hormone stimulates translocation of protein kinase C isozymes in UMR-106 osteoblastic osteosarcoma cells. Bone 29:223-230.

Dunlay R, Hruska K. 1990. PTH receptor coupling to phospholipase $\mathrm{C}$ is an alternate pathway of signal transduction in bone and kidney. Am J Physiol 258: F223-F231.

Engelse MA, Neele JM, Bronckers AL, Pannekoek H, de Vries CJ. 2001. Vascular calcification: Expression patterns of the osteoblast-specific gene core binding factor alpha- 1 and the protective factor matrix gla protein in human atherogenesis. Cardiovasc Res 52:281-289.

Erclik MS, Mitchell J. 2002. The role of protein kinase C-delta in PTH stimulation of IGF-binding protein-5 mRNA in UMR-106-01 cells. Am J Physiol Endocrinol Metab 282:E534-E541.

Fraser JD, Otawara Y, Price PA. 1988. 1, 25-Dihydroxyvitamin D3 stimulates the synthesis of matrix gammacarboxyglutamic acid protein by osteosarcoma cells. Mutually exclusive expression of vitamin K-dependent bone proteins by clonal osteoblastic cell lines. J Biol Chem 263:911-916.
Gopalakrishnan R, Ouyang H, Somerman MJ, McCauley LK, Franceschi RT. 2001. Matrix gamma-carboxyglutamic acid protein is a key regulator of PTH-mediated inhibition of mineralization in MC3T3-E1 osteoblast-like cells. Endocrinology 142:4379-4388.

Gopalakrishnan R, Suttamanatwong S, Carlson AE, Franceschi RT. 2005. Role of matrix Gla protein in parathyroid hormone inhibition of osteoblast mineralization. Cells Tissues Organs 181:166-175.

Insel PA, Ostrom RS. 2003. Forskolin as a tool for examining adenylyl cyclase expression, regulation, and G protein signaling. Cell Mol Neurobiol 23:305-314.

Ishizuya T, Yokose S, Hori M, Noda T, Suda T, Yoshiki S, Yamaguchi A. 1997. Parathyroid hormone exerts disparate effects on osteoblast differentiation depending on exposure time in rat osteoblastic cells. J Clin Invest 99: 2961-2970.

Jiang D, Franceschi RT, Boules H, Xiao G. 2004. Parathyroid hormone induction of the osteocalcin gene. Requirement for an osteoblast-specific element 1 sequence in the promoter and involvement of multiplesignaling pathways. J Biol Chem 279:5329-5337.

Jilka RL, Weinstein RS, Bellido T, Roberson P, Parfitt AM, Manolagas SC. 1999. Increased bone formation by prevention of osteoblast apoptosis with parathyroid hormone. J Clin Invest 104:439-446.

Kirfel J, Kelter M, Cancela LM, Price PA, Schule R. 1997. Identification of a novel negative retinoic acid responsive element in the promoter of the human matrix Gla protein gene. Proc Natl Acad Sci U S A 94:2227-2232.

Koh AJ, Beecher CA, Rosol TJ, McCauley LK. 1999. 3',5' Cyclic adenosine monophosphate activation in osteoblastic cells: Effects on parathyroid hormone- 1 receptors and osteoblastic differentiation in vitro. Endocrinology 140: 3154-3162.

Liu WS, Heckman CA. 1998. The sevenfold way of PKC regulation. Cell Signal 10:529-542.

Luo G, D’Souza R, Hogue D, Karsenty G. 1995. The matrix Gla protein gene is a marker of the chondrogenesis cell lineage during mouse development. J Bone Miner Res 10:325-334.

Luo G, Ducy P, McKee MD, Pinero GJ, Loyer E, Behringer RR, Karsenty G. 1997. Spontaneous calcification of arteries and cartilage in mice lacking matrix GLA protein. Nature 386:78-81.

Munroe PB, Olgunturk RO, Fryns JP, Van Maldergem L, Ziereisen F, Yuksel B, Gardiner RM, Chung E. 1999 Mutations in the gene encoding the human matrix Gla protein cause Keutel syndrome. Nat Genet 21:142-144.

Newman B, Gigout LI, Sudre L, Grant ME, Wallis GA. 2001. Coordinated expression of matrix Gla protein is required during endochondral ossification for chondrocyte survival. J Cell Biol 154:659-666.

Partridge NC, Bloch SR, Pearman AT. 1994. Signal transduction pathways mediating parathyroid hormone regulation of osteoblastic gene expression. J Cell Biochem 55:321-327.

Petryk A, Shimmi O, Jia X, Carlson AE, Tervonen L, Jarcho MP, O'Connor M.B., Gopalakrishnan R. 2005. Twisted gastrulation and chordin inhibit differentiation and mineralization in MC3T3-E1 osteoblast-like cells. Bone 36:617-626

Pfeilschifter J, Oechsner M, Naumann A, Gronwald RG, Minne HW, Ziegler R. 1990. Stimulation of bone matrix 
apposition in vitro by local growth factors: A comparison between insulin-like growth factor I, platelet-derived growth factor, and transforming growth factor beta. Endocrinology 127:69-75.

Price PA 1989. Gla-containing proteins of bone. Connect Tissue Res 21:51-7 discussion 57-60.

Radeff JM, Nagy Z, Stern PH. 2001. Involvement of PKCbeta in PTH, TNF-alpha, and IL-1 beta effects on IL-6 promoter in osteoblastic cells and on PTH-stimulated bone resorption. Exp Cell Res 268:179-188.

Renkawitz R, Gerbi SA, Glatzer KH. 1979. Ribosomal DNA of fly Sciara coprophila has a very small and homogeneous repeat unit. Mol Gen Genet 173:1-13.

Sato M, Yasui N, Nakase T, Kawahata H, Sugimoto M, Hirota S, Kitamura Y, Nomura S, Ochi T. 1998. Expression of bone matrix proteins mRNA during distraction osteogenesis. J Bone Miner Res 13:12211231.

Sato Y, Nakamura R, Satoh M, Fujishita K, Mori S, Ishida S, Yamaguchi T, Inoue K, Nagao T, Ohno Y. 2005. Thyroid hormone targets matrix Gla protein gene associated with vascular smooth muscle calcification. Circ Res 97:550-557.

Siddhanti SR, Hartle JE, 2nd, Quarles LD. 1995. Forskolin inhibits protein kinase C-induced mitogen activated protein kinase activity in MC3T3-E1 osteoblasts. Endocrinology 136:4834-4841.

Sowa H, Kaji H, Iu MF, Tsukamoto T, Sugimoto T, Chihara K. 2003. Parathyroid hormone-Smad3 axis exerts antiapoptotic action and augments anabolic action of transforming growth factor beta in osteoblasts. J Biol Chem 278:52240-52252.

Stheneur C, Dumontier MF, Guedes C, FulchignoniLataud MC, Tahiri K, Karsenty G, Corvol MT. 2003. Basic fibroblast growth factor as a selective inducer of matrix Gla protein gene expression in proliferative chondrocytes. Biochem J 369:63-70.

Sugimoto T, Ikeda K, Kano J, Yamaguchi T, Fukase M, Chihara K. 1994. Cross-talk of parathyroid hormoneresponsive dual signal transduction systems in osteoblastic osteosarcoma cells: Its role in PTH-induced homologous desensitization of intracellular calcium response. J Cell Physiol 158:374-380.
Swarthout JT, D'Alonzo RC, Selvamurugan N, Partridge NC. 2002. Parathyroid hormone-dependent signaling pathways regulating genes in bone cells. Gene 282:1-17.

Swarthout JT, Doggett TA, Lemker JL, Partridge NC. 2001. Stimulation of extracellular signal-regulated kinases and proliferation in rat osteoblastic cells by parathyroid hormone is protein kinase C-dependent. J Biol Chem 276:7586-7592.

Tam CS, Heersche JN, Murray TM, Parsons JA. 1982. Parathyroid hormone stimulates the bone apposition rate independently of its resorptive action: Differential effects of intermittent and continuous administration. Endocrinology 110:506-512.

Verheijen MH, Defize LH. 1995. Parathyroid hormone inhibits mitogen-activated protein kinase activation in osteosarcoma cells via a protein kinase A-dependent pathway. Endocrinology 136:3331-3337.

Wang A, Martin JA, Lembke LA, Midura RJ. 2000. Reversible suppression of in vitro biomineralization by activation of protein kinase A. J Biol Chem 275:1108211091.

Wang D, Christensen K, Chawla K, Xiao G, Krebsbach PH, Franceschi RT. 1999. Isolation and characterization of MC3T3-E1 preosteoblast subclones with distinct in vitro and in vivo differentiation/mineralization potential. J Bone Miner Res 14:893-903.

Winchester SK, Bloch SR, Fiacco GJ, Partridge NC. 1999. Regulation of expression of collagenase-3 in normal, differentiating rat osteoblasts. J Cell Physiol 181:479_ 488.

Xiao G, Jiang D, Thomas P, Benson MD, Guan K, Karsenty G, Franceschi RT. 2000. MAPK pathways activate and phosphorylate the osteoblast-specific transcription factor, Cbfa1. J Biol Chem 275:4453-4459.

Yagami K, Suh JY, Enomoto-Iwamoto M, Koyama E, Abrams WR, Shapiro IM, Pacifici M, Iwamoto M. 1999. Matrix GLA protein is a developmental regulator of chondrocyte mineralization and, when constitutively expressed, blocks endochondral and intramembranous ossification in the limb. J Cell Biol 147:1097-1098.

Yoon S, Seger R. 2006. The extracellular signal-regulated kinase: Multiple substrates regulate diverse cellular functions. Growth Factors 24:21-44. 